\title{
Aplikasi Sms Gateway Untuk Mengakses Informasi Nilai Ujian Akhir Nasional Pada Smp YP. Fatahillah Cilegon
}

\author{
Akip Suhendar ${ }^{1}$ \\ ${ }^{1}$ Program Studi Teknik Informatika, Fakultas Teknologi Informasi- Universitas Serang Raya \\ Jl. Raya Cilegon - Serang Km.5 Taman Drangong Kota serang - Banten, indonesia \\ ${ }^{1}$ akip. suhendaregmail.com
}

\begin{abstract}
Kemajuan teknologi telekomunikasi pada saat ini memiliki pengaruh yang sangat besar terhadap perkembangan informasi. Handphone merupakan salah satu perangkat telekomunikasi yang sedang berkembang pada saat ini. Apalagi banyak, atau sudah bisa dibilang hampir seluruh handphone yang dipasarkan sudah memiliki kemampuan untuk dihubungkan dengan sebuah komputer dengan menggunakan koneksi tertentu. Koneksi tersebut bisa berupa kabel data, infrared ataupun bluetooth.

SMS (Short Message service) merupakan salah satu media pada GSM (Global Sistem of Mobile communication) yang memungkinkan seseorang untuk dapat mengirim pesan antar pengguna telepon genggam. SMS merupakan media yang paling banyak dipakai oleh pengguna karena hampir setiap telepon genggam (Handphone) memiliki fasilitas ini.

Pada saat ini pengumuman nilai ujian akhir nasional pada SMP Y.P Fatahillah Cilegon menggunakan surat panggilan yang ditujukan kepada orang tua atau wali murid, sehingga diharapkan wali murid dapat hadir pada saat pengumuman nilai nilai ujian akhir nasional yang telah ditentukan oleh pihak sekolah dan mencegah aksi corat-coret baju yang dijadikan tradisi oleh murid-murid sekolah pada saat pengumuman nilai ujian, namun hal tersebut mengalami beberapa kendala diantaranya ialah biaya yang harus dikeluarkan oleh pihak sekolah dalam pembuatan surat undangan untuk para orangtua dan adanya kesibukan para orangtua yang tidak dapat ditinggalkan serta seringnya terjadi keterlambatan dalam proses pengiriman surat sehingga menghambat orangtua atau murid untuk mendapatkan informasi nilai ujian akhir nasional secara cepat.

Penelitian ini menghasilkan sebuah program aplikasi SIUAN yang dapat mengatasi permasalahan yang ada dengan memanfaatkan layanan SMS (Short Message Service) agar dapat digunakan untuk mengakses informasi nilai ujian akhir nasional secara cepat dengan biaya yang sangat murah.
\end{abstract}

Kata Kunci : Teknologi Komunikasi, Handphone, SMS, Nilai ujian Akhir Nasional.

\section{LATAR BELAKANG}

Kemajuan teknologi komunikasi pada saat ini memiliki pengaruh yang sangat besar terhadap perkembangan informasi. Hal tersebut merupakan salah satu pemicu untuk terus bersaing menguasai berbagai teknologi informasi dan komunikasi. Semakin cepat informasi didapatkan, maka bekal untuk maju mulai terpenuhi, apalagi teknologi komunikasi yang semakin canggih dengan terciptanya perangkatperangkat telekomunikasi yang sangat bervariasi.

Didukung lagi dengan semakin banyaknya perangkat telekomunikasi yang memiliki kemampuan khusus, diantaranya adalah handphone dan PDA (Personal Digital Assistant ). Pada saat ini banyak, atau sudah bisa dibilang hampir seluruh handphone dan PDA (Personal Digital Assistant ) yang dipasarkan sudah memiliki kemampuan untuk dihubungkan dengan sebuah komputer menggunakan koneksi tertentu. Koneksi tersebut bisa berupa kabel data, infrared ataupun bluetooth. Meskipun bentuk dari hanphone semakin hari dirancang semakin kecil namun hal tersebut tidak mengurangi kemampuan yang dimiliki alat tersebut. Diantaranya ialah aplikasi layanan SMS (Short Message Service) yang dapat di manfaatkan untuk mengakses informasi yang diinginkan secara cepat.

Hal diatas dapat dimanfaatkan untuk meningkatkan kemampuan dari sebuah alat telekomunikasi dengan menggunakan koneksi yang ada, serta membuat aplikasi tambahan di perangkat itu sendiri maupun di komputer, karena banyak tersedia tools yang bisa digunakan untuk membuat aplikasi tersebut.

Oleh karena kebutuhan manusia untuk dapat mengakses informasi yang dibutuhkan secara cepat dan akurat, maka banyak pengguna handphone yang menginginkan adanya aplikasi yang bisa digunakan untuk mengakses informasi secara cepat dan akurat serta dengan biaya yang sangat murah seperti aplikasi layanan SMS, karena sebagian dari pengguna handphone tidak suka menunggu terlalu lama ketika ingin mendapatkan informasi secara langsung dan akurat. Permasalahan yang timbul tersebut dapat diatasi dengan merancang sebuah aplikasi pada komputer untuk dapat memberikan informasi yang akurat secara otomatis kepada para pengguna, ketika para pengguna mengirimkan pesan berupa SMS dengan kode tertentu, tentu saja aplikasi yang dirancang ini harus di dukung dengan adanya koneksi yang tersedia antara handphone dengan komputer. 


\section{DASAR TEORI}

A. Short Message Service ( SMS )

Short Message service ( SMS ) adalah sebuah layanan untuk pengiriman pesan pendek melalui jaringan GSM (Global Sistem of Mobile Communication) yang distandarisasi oleh ETSI (European Telecomunication Standard Institute) sehingga setiap pengguna handphone dapat melakukan pengiriman pesan. SMS pertama kali dikembangkan di Eropa sekitar tahun 1991, sehingga dijadikan sebagai sebuah standar untuk pengiriman pesan dengan menggunakan jaringan GSM.

Di Amerika Utara, layanan SMS ini pada awalnya di pelopori oleh beberapa perusahaan, seperti BellSouth Mobility, PrimeCo, dan Nextel dengan berdasarkan pada standar jaringan GSM, CDMA ( Code Division Multiple Access), TDMA ( Time Division Multiple Access ). Dengan adanya kerjasama antar para pelopor layanan tersebut, maka layanan SMS semakin berkembang dan bisa digunakan dimana saja, asalkan masih didalam jangkauan penyedia layanan atau penyedia layanan lain yang telah melakukan kerjasama untuk saling mendukung. Setiap SMS yang dikirim akan melalui sebuah SMS Center ( SMSC ) yang berfungsi sebagai pengelola dan pengontrol setiap SMS yang akan dikirim ke nomor tujuan dan akan melakukan notifikasi kembali kepada pengirim jika SMS telah diterima oleh nomor tujuan, atau akan melakukan pengiriman ulang selama masa validasi pesan jika nomor tujuan tidak dapat dihubungi.

\section{B. Aplikasi SMS interaktif}

Aplikasi SMS interaktif merupakan sebuah program yang digunakan untuk melakukan komunikasi dua arah dengan memanfaatkan layanan SMS ( Short Message Service) agar program tersebut dapat membantu memudahkan seseorang dalam melaksanakan sebuah pekerjaan.

\section{Java Servlet}

Java merupakan bahasa pemrograman yang sangat populer saat ini. Pemrograman java memiliki kemampuan dalam menciptakan aplikasi grafis, web dan database serta kelebihan java yang dapat berjalan sistem operasi apapun membuat bahasa pemrograman ini banyak digunakan.

Pemrograman Java pertama kali dikembangkan oleh James Gosling dari Sun Microsistems pada tahun 1990-an. Bahasa pemrograman ini pertama kali dikembangkan untuk memenuhi kebutuhan bahasa computer yang satu kali dan dapat dijalankan pada banyak sistem computer. Sejak pertama kali dikembangkan Java telah memiliki dua generasi yaitu :

a) J2EE (Java 2 Enterprise Edition)

J2EE biasa digunakan pada pemrograman aplikasi server, atau aplikasi berbasis web server.

b) J2SE (Java 2 Standard Edition)

Paket ini paling banyak digunakan pada pembuatan aplikasi desktop.

c) J2ME (Java 2 Micro Edition)
Paket ini biasa digunakan untuk pembuatan aplikasi pada wireless device atau mobile device.

Servlet merupakan salah satu teknologi yang dimiliki oleh pemrograman JAVA dan merupakan salah satu teknologi yang penting dari J2EE karena menjadi dasar dari teknologi JSP (Java Server Pages). Pada saat ini teknologi java dapat dikatakan telah mendominasi teknologi enterprise (J2EE) karena teknologi ini terbukti tangguh dan stabil dalam aplikasi enterprise. Sehingga penguasaan teknologi ini sangatlah penting terutama untuk pengembangan komponen web (servlet dan JSP).

Servlet sering digunakan untuk menghasilkan response berupa halaman HTML, XML, file dan sebagainya sesuai request yang berjalan pada protocol HTTP. Untuk dapat menjalankan aplikasi ini diperlukan bahasa pemrograman java dan Servlet Container. Salah satu servlet container yang terkenal dan paling banyak digunakan adalah Apache Tomcat.

\subsection{NOW SMS GATEWAY}

NOW SMS merupakan sebuah aplikasi yang berfungsi sebagai SMS gateway antara handphone terminal dengan servlet, sehingga SMS yang diterima handphone dapat di proses oleh aplikasi ini dan diteruskan ke servlet. Untuk koneksi yang digunakan oleh handphone dan komputer ialah dengan memanfaatkan bluetooth. Pada aplikasi NOW SMS ini memiliki fitur yang mendukung 2-way SMS untuk membangun sebuah aplikasi interaktif. Selain itu aplikasi juga mendukung penggabungan SMS untuk teks yang melebihi 160 karakter atau dapat dikatakan menjadi 2 kali pengiriman..

\section{KERANGKA PIKIR}

Keinginan pihak SMP Fatahilah dalam menyajikan informasi yang dapat diakses secara cepat dan akurat serta mudah dalam pengaksesannya menjadi salah satu pemicu untuk melakukan perancangan sebuah aplikasi SIUAN (SMS Interaktif Ujian Akhir Nasional). Pada aplikasi SIUAN ini, ketika siswa ingin mendapatkan informasi nilai ujian akhir nasional seorang siswa cukup mengirimkan SMS dengan format yang telah ditentukan kepada hanphone yang digunakan sebagai terminal atau modem, kemudian SMS tersebut akan di proses oleh SMS Gateway yang diteruskan pada servlet yang fungsinya adalah untuk memeriksa apakah SMS yang dikirim sesuai dengan format yang telah ditentukan, jika SMS yang dikirimkan sesuai dengan format yang telah ditentukan maka servlet akan mencari isi data dalam database sesuai permintaan dari siswa, selanjutnya servlet akan mengirimkan data yang telah diakses dari database ke SMS Gateway dan selanjutnya diteruskan pada handphone terminal yang akan mengirimkan SMS balasan sesuai permintaan. Namun jika SMS yang dikirimkan tidak sesuai dengan format yang telah ditentukan maka siswa akan mendapatkan SMS 
balasan berupa pesan kesalahan yang telah ditentukan pada servlet.

\section{TEKNIK DAN PROSES PENGUMPULAN DATA.}

Pada penelitian ini proses pengumpulan data yang dilakukan penulis ialah dengan menggunakan metode wawancara dengan pihak SMP YP. Fatahillah yang diwakili oleh ketua panitia Ujian Akhir Nasional tahun 2008 ini. Selain itu penulis melakukan observasi pada SMP YP. Fatahillah dalam usaha melakukan pengumpulan data-data yang diperlukan untuk melakukan perancangan aplikasi SIUAN. Dari proses pengumpulan data tersebut penulis mendapatkan beberapa data yang diperlukan diantaranya ialah jumlah mata pelajaran yang akan diikutsertakan pada Ujian Akhir Nasional tahun pelajaran 2007-2008 ini. Selain itu data jumlah siswa pada SMP YP. Fatahillah yang akan mengikuti Ujian Akhir Nasional. Sehingga data-data tersebut dapa membantu dalam melakukan perancangan aplikasi SIUAN.

\section{AnAlisis Dan PERANCANGAN Sistem}

\section{A. Instrumen Penelitian.}

Dalam perancangan aplikasi SIUAN ( SMS interaktif Ujian Akhir Nasional ) ini digunakan beberapa perlatan yang dibutuhkan, diantaranya ialah Bluetooth USB Adapter yaitu sebuah hardware tambahan pada komputer yang berfungsi agar komputer dapat saling berkomunikasi atau berhubungan dengan perangkat lain yang memiliki koneksi bluetooth. Kemudian untuk perangkat pendukung lain pada aplikasi SIUAN ini penulis menggunakan sebuah ponsel Sony Ericcson K-700i yang fungsinya ialah sebagai GSM modem, dan ponsel ini memiliki koneksi bluetooth sehingga nantinya ponsel ini akan terhubung dengan komputer menggunakan koneksi bluetooth.

\section{B. Analisa Masukan}

Pada aplikasi SIUAN ini terdapat data masukan yaitu berupa SMS yang dikirimkan oleh pengguna, dalam hal ini ialah siswa. SMS yang akan menerima balasan berupa informasi Nilai Ujian Akhir Nasional ialah SMS yang sesuai dengan format yang telah ditentukan. Pada aplikasi SIUAN ini keyword yang digunakan ialah (UAN) sehingga jika seorang siswa ingin mengkases nilai Ujian Akhir Nasional maka siswa tersebut harus mengirimkan SMS dengan keyword dan diikuti oleh NIS (Nomor Induk Siswa)..

\section{Analisa Keluaran}

Pada aplikasi SIUAN ini terdapat pula data keluaran yaitu berupa informasi nilai Ujian Akhir Nasional atau pesan kesalahan. Jika SMS yang dikirim tidak sesuai atau tidak menggunakan keyword yang telah ditentukan maka akan mendapatkan SMS balasan berupa pesan kesalahan, namun jika siswa tersebut telah mengirimkan SMS dengan keyword yang benar tetapi Nomor Induk Siswa tidak benar maka akan mendapatkan SMS balasan berupa pesan kesalahan 2 . untuk lebih jelasnya dapat dilihat pada gambar dibawah ini.

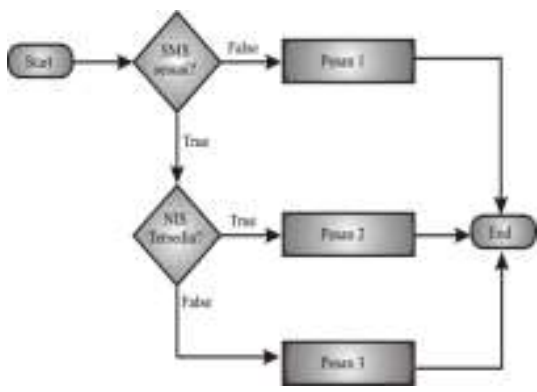

Gambar 3.1 Alur pesan

Keterangan alur balasan SMS:

Tabel 3.1 Isi Pesan balasan

\begin{tabular}{|c|c|c|}
\hline $\begin{array}{c}\text { No } \\
\text { Pesan }\end{array}$ & Isi Pesan & Keterangan \\
\hline $\begin{array}{c}\text { Pesan } \\
1\end{array}$ & $\begin{array}{l}\text { Keyword yang anda masukan } \\
\text { salah, Ketik } \\
\text { UAN<spasi>NO_INDUK_- } \\
\text { SISWA contoh: UAN } 1234567\end{array}$ & $\begin{array}{l}\text { Pesan } \\
\text { kesalahan } \\
\text { jika keyword } \\
\text { salah }\end{array}$ \\
\hline $\begin{array}{l}\text { Pesan } \\
2\end{array}$ & $\begin{array}{l}\text { "< } \text { nama_siswa }>" \\
\text { B.Indonesia }:<\text { bindo }> \\
\text { Matematika }:<\text { mat }>\text { B.Inggris : } \\
<\text { bing }>\text { IPA }:<\text { ipa }> \\
\text { Jumlah }:<\text { jml }>\text { Status: }<\text { status }>\end{array}$ & $\begin{array}{l}\text { Pesan } \\
\text { balasan jika } \\
\text { Keyword } \\
\text { benar dan } \\
\text { Nomor } \\
\text { Induk Siswa } \\
\text { Tersedia }\end{array}$ \\
\hline $\begin{array}{l}\text { Pesan } \\
3\end{array}$ & $\begin{array}{l}\text { Maaf, Nomor Induk Siswa yang } \\
\text { anda maksud tidak terdapat } \\
\text { dalam database kami. }\end{array}$ & $\begin{array}{l}\text { Pesan } \\
\text { balasan jika } \\
\text { keyword } \\
\text { benar namun } \\
\text { Nomor } \\
\text { Induk Siswa } \\
\text { tidak } \\
\text { tersedia. }\end{array}$ \\
\hline
\end{tabular}

\section{Analisa Proses}

Analisa proses menjelaskan tentang proses yang terjadi pada sebuah aplikasi, dimana akan digambarkan sistem kerja dari sebuah aplikasi. Pada penelitian ini proses kerja dari aplikasi SIUAN lebih tertumpu pada kinerja server, sehingga setiap SMS yang dikirim kepada terminal akan dikelola sepenuhnya oleh server. Untuk proses kerja dari server akan di gambarkan seperti dibawah ini : 


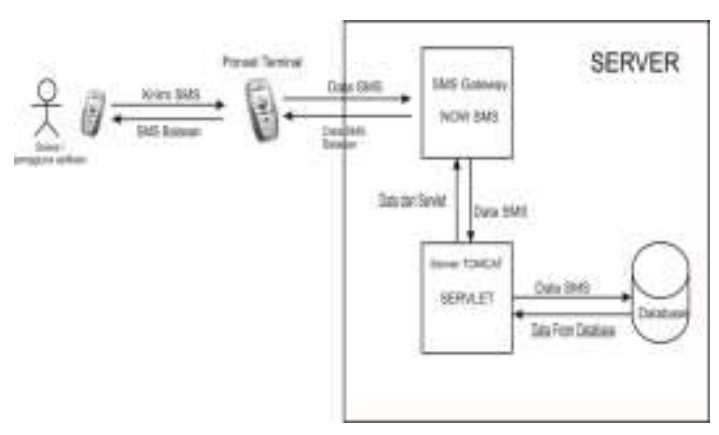

Keterangan :

a) Pengguna dalam hal ini siswa, mengirimkan SMS pada Handphone terminal.

b) SMS Gateway akan mendeteksi adanya SMS yang diterima oleh Handphone terminal, kemudian akan meneruskan isi SMS pada servlet yang menghandle. ( SMS Gateway melakukan http request ke servlet), dengan parameter "msisdn" yang berisi nomor telepon pengirim dan parameter "sms" yang berisi SMS dari pengirim melalui alamat URL.

c) Dari SMS yang masuk tiap SMS akan dipecah oleh servlet ke dalam array string dengan delimeter spasi.

d) Setelah isi SMS yang dikirim diproses oleh servlet, kemudian tugas servlet adalah membuka koneksi http client ke SMS Gateway untuk mengirim SMS balasan (servlet memberikan http response kepada SMS Gateway) dan meneruskannya pada handphone terminal dan selanjutnya akan dikirim ke hanphone pengguna.

Struktur Tabel Nilai

Tabel 3.2 Struktur Tabel Nilai

\begin{tabular}{|c|c|c|c|c|c|c|c|}
\hline $\begin{array}{c}\text { nis } \\
*\end{array}$ & $\begin{array}{c}\text { Na } \\
\text { ma }\end{array}$ & Bindo & Mat & Bing & IPA & Jml & Status \\
\hline & & & & & & & \\
\hline
\end{tabular}

\begin{tabular}{|l|c|c|lll|}
\hline $\begin{array}{c}\text { Fiel } \\
\text { d }\end{array}$ & $\begin{array}{c}\text { Jenis } \\
\text { Data }\end{array}$ & L & \multicolumn{3}{|c|}{ Keterangan } \\
\hline $\begin{array}{l}\text { nis } \\
*\end{array}$ & Char & 7 & Berisi Nomor Induk Siswa \\
\hline $\begin{array}{l}\text { na } \\
\text { ma }\end{array}$ & Char & 2 & Berisi Nama Siswa & \\
\hline $\begin{array}{l}\text { bin } \\
\text { do }\end{array}$ & Char & 5 & $\begin{array}{l}\text { Berisi Nilai mata } \\
\text { bahasa Indonesia }\end{array}$ & pelajaran \\
\hline mat & Char & 5 & $\begin{array}{l}\text { Berisi Nilai mata } \\
\text { Matematika }\end{array}$ & pelajaran \\
\hline $\begin{array}{l}\text { bin } \\
\text { g }\end{array}$ & Char & 5 & $\begin{array}{l}\text { Berisi Nilai mata } \\
\text { bahasa Inggris }\end{array}$ \\
\hline ipa & Char & 5 & $\begin{array}{l}\text { Berisi Nilai mata pelajaran Ilmu } \\
\text { Pengetahuan Alam }\end{array}$ \\
\hline
\end{tabular}

\begin{tabular}{|l|c|c|l|}
\hline jml & Char & 5 & $\begin{array}{l}\text { Berisi Jumlah Nilai dari seluruh } \\
\text { mata pelajaran. }\end{array}$ \\
\hline $\begin{array}{l}\text { Stat } \\
\text { us }\end{array}$ & $\begin{array}{c}\text { Tinyi } \\
\text { nteger }\end{array}$ & 2 & $\begin{array}{l}\text { Berisi Nilai (1) dan (0), atau } \\
\text { keterangan Lulus atau Tidak. }\end{array}$ \\
\hline
\end{tabular}

\section{HASIL DAN PEMBAHASAN}

Pada penelitian ini menghasilkan sebuah aplikasi SMS Interaktif untuk mengakses informasi nilai ujian akhir nasional (SIUAN). Aplikasi SIUAN dirancang untuk memenuhi kebutuhan pihak SMP YP.Fatahillah Cilegon dalam usaha menyajikan informasi nilai ujian akhir nasional agar dapat diakses secara cepat dan akurat oleh para siswa maupun wali murid.

Berdasarkan hasil wawancara dengan pihak SMP YP.Fatahillah Cilegon yang diwakili oleh ketua panitia Ujian Akhir Nasional, ditememukan adanya sebuah permasalahan pada saat penyampaian atau pengumuman nilai ujian akhir nasional, akibat dari permasalahan tersebut terdapat beberapa siswa masih belum dapat mengetahui nilai ujian nasional tepat pada waktunya. Hal tersebut disebabkan oleh sistem pengumuman nilai ujian akhir nasional pada SMP YP.Fatahillah Cilegon saat ini ialah dengan memberikan surat pemberitahuan kepada wali murid agar dapat hadir untuk menerima nilai ujian akhir nasional siswa, namun terdapat orang tua atau wali murid yang berhalangan hadir dikarenakan kegiatan atau tanggung jawab tugas masing-masing sehingga menghambat siswa untuk dapat mengetahui nilai ujian akhir nasional.

Dengan menggunakan aplikasi SIUAN pihak sekolah dapat menyediakan informasi nilai ujian akhir nasional yang dapat diakses para siswa maupun wali murid dengan cepat dan akurat, sehingga tidak ada lagi permasalahan yang menghambat pengumuman nilai ujian akhir nasional.

\section{A. Tampilan kompilasi dengan ant}

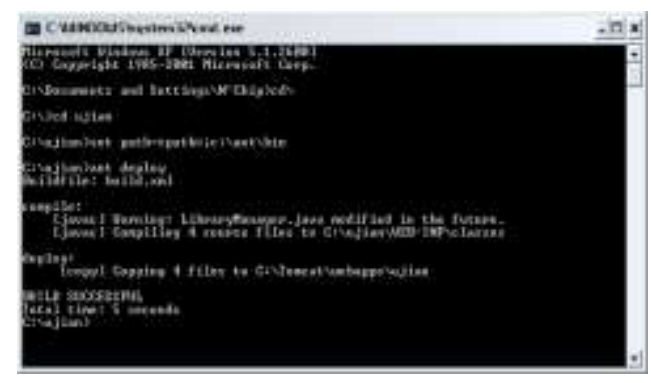

Gambar 4.1 Tampilan kompilasi 


\section{B. tampilan servlet yang berjalan}

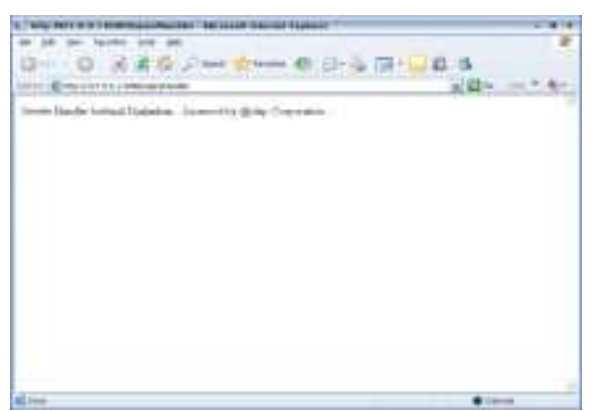

Gambar 4.2 Tampilan saat servlet dijalankan melalui Internet Explorer.

C. tampilan pesan kirim dan balasan ke user
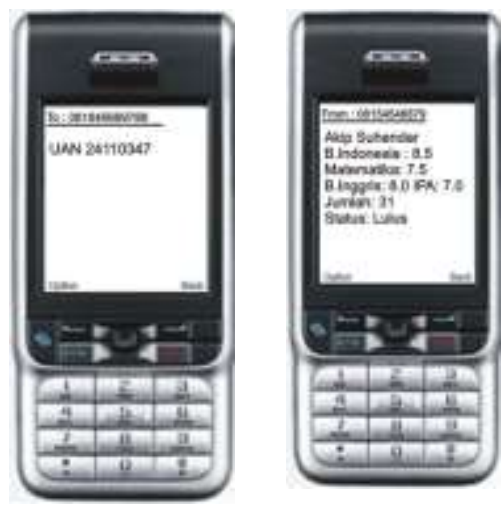

VII. KESIMPULAN

Dari seluruh penjelasan dan uraian yang telah dicantumkan maka dapat disimpulkan bahwa :

a) Aplikasi SIUAN ini dapat membatu siswa dan wali murid dalam mengkases nilai ujian akhir nasional secara cepat dan mudah.

b) Aplikasi SIUAN dapat membantu pihak SMP YP. Fatahillah dalam usaha menyediakan informasi yang dapat diakses 24 jam.

c) Untuk mengetahui nilai ujian akhir nasional siswa dan wali murid dapat memanfaatkan teknologi SMS serta biaya yang dikeluarkan sangat murah

\section{DAFTAR PUSTAKA}

[1] Al-Bahra, "Konsep Sistem Basis Data dan Implementasinya", Graha Ilmu, Yogyakarta, 2004.

[2] Djamarudin, Nasroelah,"Metodologi Penelitian", Serang:CV Daffa Putra 2006.

[3] Irawan, “ Java Untuk Orang Awam”, Maxikom, Palembang, 2007.

[4] Rickyanto Isak, "Pemrograman Web dengan Java Servlet", Andi, $\quad$ Yogyakarta, 2003.
[5] Ardian (2003). "Aplikasi SMS (Short Message Service) Manager Berbasis Java Pada Personal Komputer". Abstraksi, Diakses 04 Maret 2008 dari http://www.ti.usd.ac.id/skripsi/home/temp..php?id=876

[6] Heryanto (2004), "Sistem Perdagangan Multilevel Dengan Memanfaatkan Layanan Sms (Short Message Service)", Abstrak, Diakses 26 Maret 2008 dari skripsi.iufpn.com

[7] http://skripsi.ifupn.com/main_detailskipsiselesai.php ?nomhs $=123010102$

[8] Martina (2004), “Aplikasi Enkripsi Dan Deskripsi (Short Message Service) SMS”. Abstraksi, Diakses 04 Maret 2008 dari ti.usd.ac.id. http://www.ti.usd.ac.id/skripsi/home/temp..php?id=910

[9] Teddy Setya Nugraha(2008). "Laporan Proyek Khusus". Artikel,Diakses 27 april 2008,21.00dari http://teddyabout.web.ugm.ac.id/download/BAB\%20II.p df

[10] Valzki (2005), "Sistem Informasi Jadwal Konsultasi Dokter Via Sms.” Abstraksi, Diakses 09 April 2008. 